\title{
BREVE ANÁLISE DAS PUBLICAÇÕES DA REVISTA HISTEDBR ON- LINE AO LONGO DE SUAS EDIÇÕES
}

Taciana Brasil dos Santos ${ }^{1}$

\section{RESUMO}

Este artigo tem por objetivo realizar uma breve análise do conteúdo da Revista HISTEDBR On-line, desde sua criação, em 2000, até o último número de 2011. Para isso, será realizado um levantamento dos números do periódico, elencando-se alguns deles a fim de realizar uma análise das transformações ocorridas no periódico ao longo dos anos. Serão consideradas as mudanças no corpo editorial e autoral, além das linhas de pesquisa, normas, tipos e quantidades de publicações veiculadas.

Palavras-chave: periódico; história da educação; publicações.

\section{A BRIEF ANALYSIS OF THE PUBLICATIONS OF THE JOURNAL HISTEDBR ON-LINE OVER YOUR EDITS}

\begin{abstract}
This article aims to make a brief review of the contents of the Journal HISTEDBR On-line since its inception in 2000 until the last issue of 2011 . This will be a survey of the numbers of the journal, listing a few of them in order to perform an analysis of changes occurring in the journal over the years. Will be considered changes in editorial and authorial, and research areas, standards, quantities and types of publications disseminated.
\end{abstract}

Keywords: journal, history of education, publications.

Uma das primeiras revistas do campo de História da Educação em formato exclusivamente digital neste país, a revista HISTEDBR On-line é uma publicação do Grupo de Estudos e Pesquisas História, Sociedade e Educação no Brasil. Este grupo foi criado em 1986, sendo sediado na Faculdade de Educação da UNICAMP. Inicialmente, promovia encontros semestrais entre seus participantes, para debater a elaboração de suas pesquisas. Posteriormente, constituiu-se em um grupo de pesquisas em âmbito nacional, articulando vários Grupos de Trabalho regionais e estaduais. A partir de então, tem realizado encontros de apresentação e debate de pesquisas, além de desenvolvimento de Projetos, Colóquios, Jornadas, Encontros, Seminários, e a revista eletrônica, objeto desta pesquisa $^{2}$.

A revista HISTEDBR On-line circula desde setembro de 2000 ininterruptamente, com algumas variações de organização e configuração. As figuras a seguir demonstram a única mudança de aparência da página da revista, durante o período analisado. 


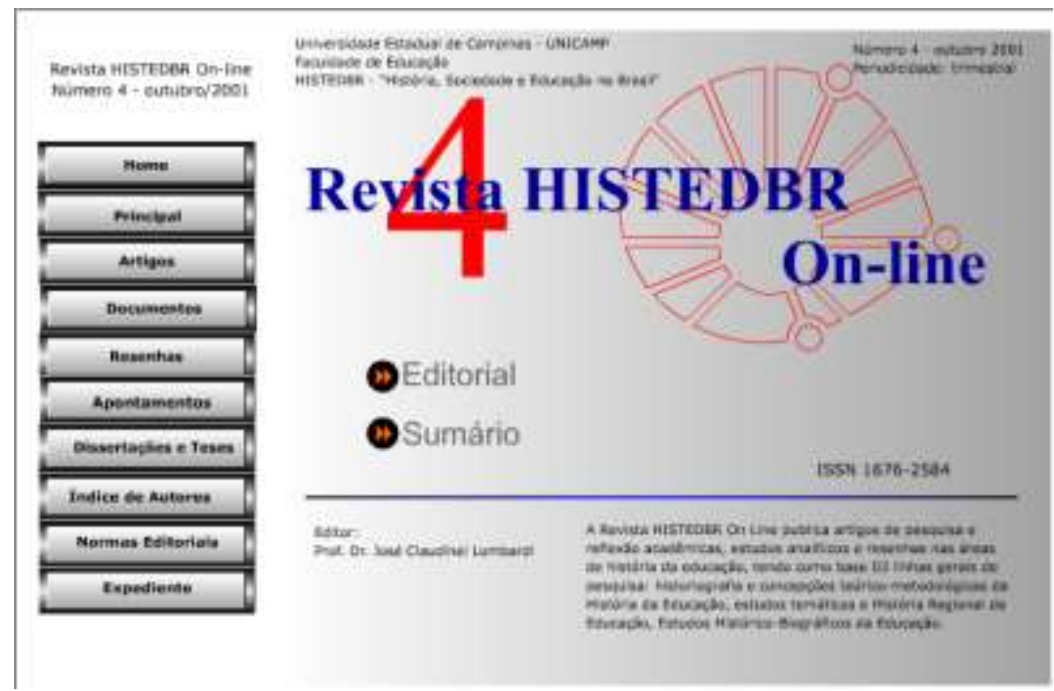

Figura 1 - Aparência inicial da Revista HISTEDBR On-line.

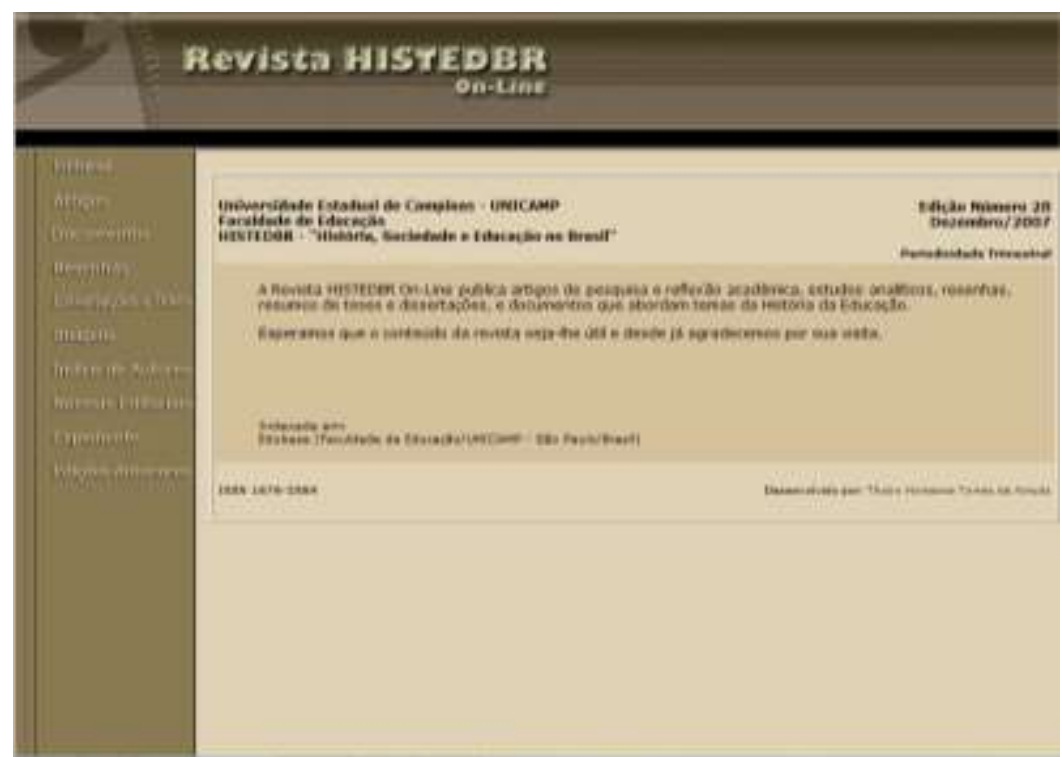

Figura 2 - Aparência da Revista HISTEDBR On-line a partir do número 28 (dez/2007) até o último número analisado (n. 44, dez/2011).

Desde sua criação, a Revista HISTEDBR On-line tem adotado a periodicidade trimestral, sendo que até dezembro de 2011 conta com 44 números regulares e cinco especiais, com um total de 704 artigos.

\section{Corpo editorial da Revista HISTEDBR On-line}

Percebe-se, ao longo das edições da revista, uma estabilidade dos indivíduos que compõe o corpo editorial - embora tenha havido um crescimento numérico significativo destes ao longo do tempo. Este crescimento veio acompanhado de um aumento e transformação dos cargos. No número 04 (out/2001), o corpo editorial da revista era composto por cinco pessoas, e o Conselho Editorial era o próprio grupo HISTEDBR. Destes cinco, quatro permaneceram na revista até o último número analisado. O Editor 
Responsável dos primeiros números da revista, professor José Claudinei Lombardi, mantém-se no cargo até o último número analisado, embora a partir do número 23 (set/2006) dividisse o cargo com a professora Maria Isabel Moura Nascimento. Observando a seção Expediente do número 24 (dez/2006), percebe-se que o Conselho Editorial é composto de 34 integrantes, de diversas instituições de ensino superior de todo o país. No número 44 (dez/2011), o Conselho Editorial é composto pelo grupo original de 04 integrantes que permaneceram ao longo das edições da revista, e a Comissão Editorial é composta de 95 doutores, em sua maioria professores de instituições de ensino superior.

A partir de uma análise de pertencimento dos membros do Conselho Editorial do número 24 (dez/2006) e a Comissão Editorial do número 44 (dez/2011), pode-se perceber que a maioria deles é professor de universidades federais ou estaduais. É importante considerar que nem todos os membros do número mais recente são docentes: dois deles não possuem vínculo institucional descrito, um é membro do Conselho Estadual de Educação do Paraná, e um é funcionário da Secretaria de Cultura de São Paulo. O gráfico abaixo registra, em um esquema comparativo de porcentagens, o número de docentes de cada tipo de instituição de ensino superior nos grupos analisados:

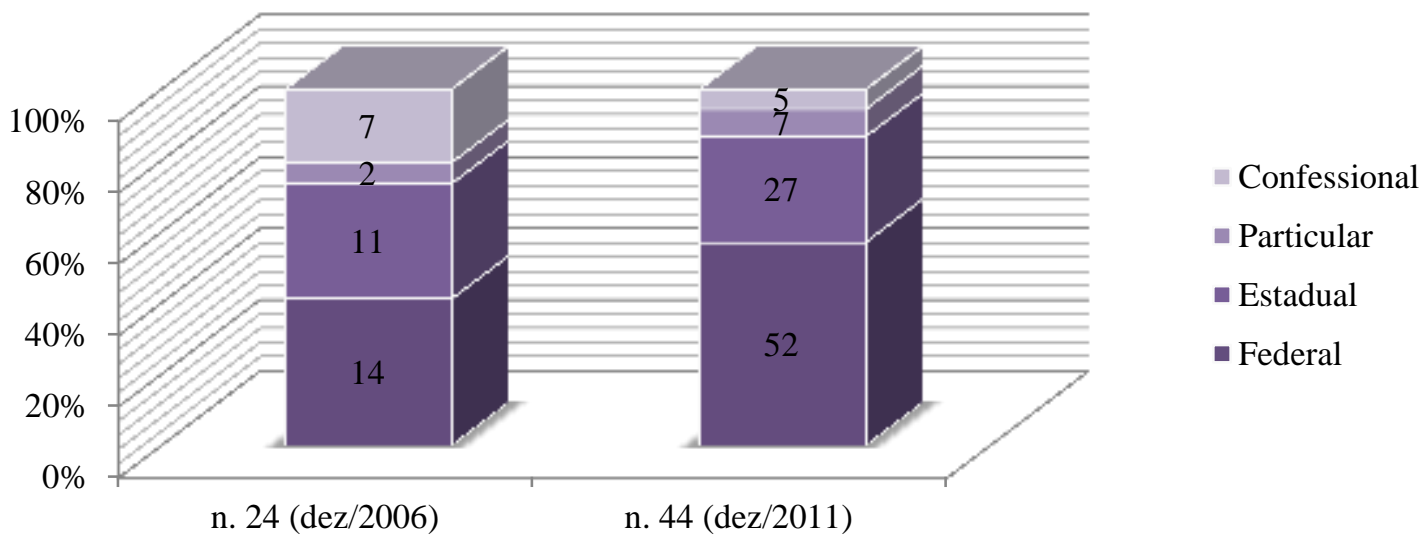

Figura 3 - Pertencimento institucional dos docentes membros do Conselho Editorial (n. 24, dez/2006) e Comissão Editorial (n. 44, dez/2011) da Revista HISTEDBR On-line. A partir do tipo de instituição.

Como se pode perceber, apesar das diferenças numéricas entre os grupos, os docentes de universidades federais são a maioria em ambos os casos, seguidos pelos docentes de universidades estaduais, instituições particulares e instituições confessionais. Percebe-se ainda o aumento percentual de indivíduos vinculados a instituições federais, e uma diminuição - percentual e numérica - de professores ligados a instituições confessionais. Este pode ser um dado importante, que talvez indique mudanças nas futuras publicações da revista - cabe considerar que a HISTEDBR On-line é uma das revistas do campo de história da educação que mais publica artigos que tratam de temas relacionados à influência da religião na educação, $11,29 \%$ do total. $\mathrm{E}$ muitos destes artigos são relacionados aos mesmos seguimentos religiosos aos quais as instituições confessionais que possuem membros no Conselho/Comissão Editorial se vinculam

Ainda analisando este mesmo grupo, pode-se perceber que nele estão representadas instituições de todas as regiões geográficas do Brasil - apesar das diferenças numéricas e dos tipos de instituições em cada uma delas. 


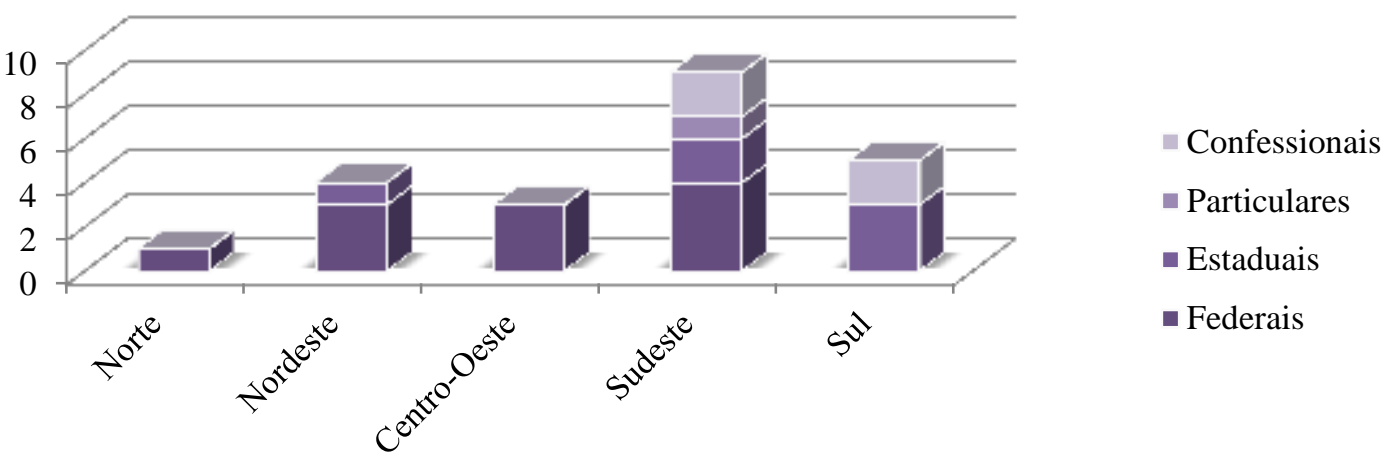

Figura 4 - Tipos de instituições de ensino superior relacionadas entre os membros do Conselho Editorial da Revista HISTEDBR On-line n. 24 (dez/2016)

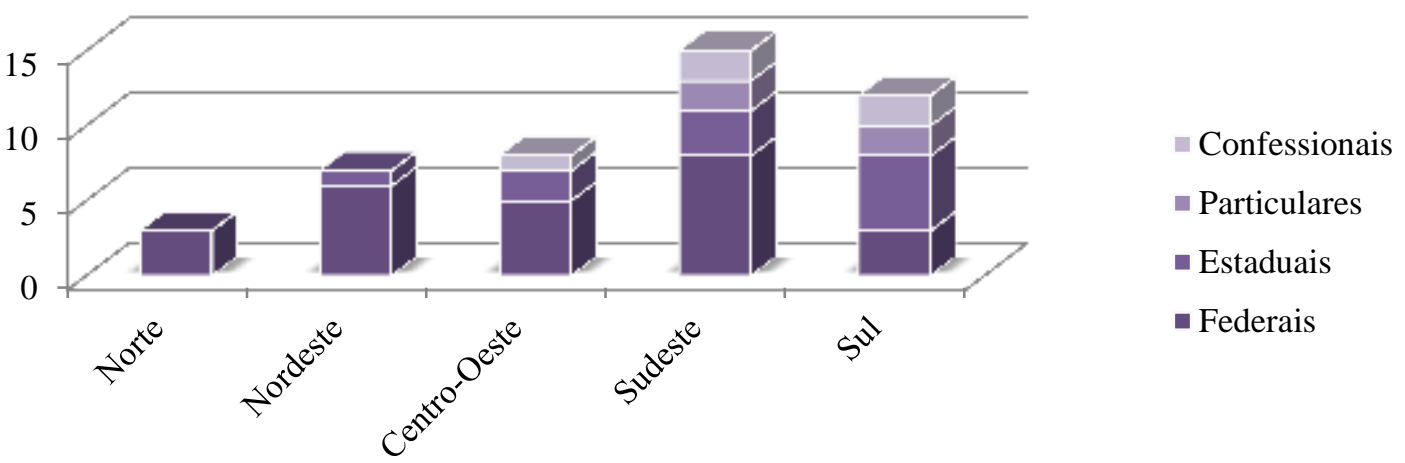

Figura 5 - Tipos de instituições de ensino superior relacionadas entre os membros da Comissão Editorial da Revista HISTEDBR On-line n. 44 (dez/2011)

Em ambos os gráficos percebe-se que a região Sudeste é a mais influente em número de instituições representadas, e a única que conta com os quatro tipos de instituições de ensino superior relacionados. As regiões Sudeste e Sul são as mais expressivas numericamente. Comparando os gráficos, pode-se verificar uma evolução numérica e em tipos de instituições na representação das regiões brasileiras.

Analisando o número de representantes por região, chega-se a outras conclusões. Percentualmente, este número não sofreu alterações significativas - destaca-se apenas ligeiro declínio no percentual de participantes da região Sudeste e crescimento entre os participantes da região Centro-Oeste. Considerando o número absoluto, percebe-se que em todas as regiões - exceto a Sudeste - o número de participantes no mínimo triplicou em relação a 2006. Destaca-se a região Centro-Oeste, cujo crescimento foi o maior entre as regiões brasileiras. A região Sudeste, embora continue a mais numerosa, teve o menor crescimento percentual no número de participantes - pouco mais de $100 \%$. Se a participação no editorial da revista continuar crescendo nessas proporções, no futuro é bastante provável que haja uma equivalência na participação entre as regiões do Brasil. 


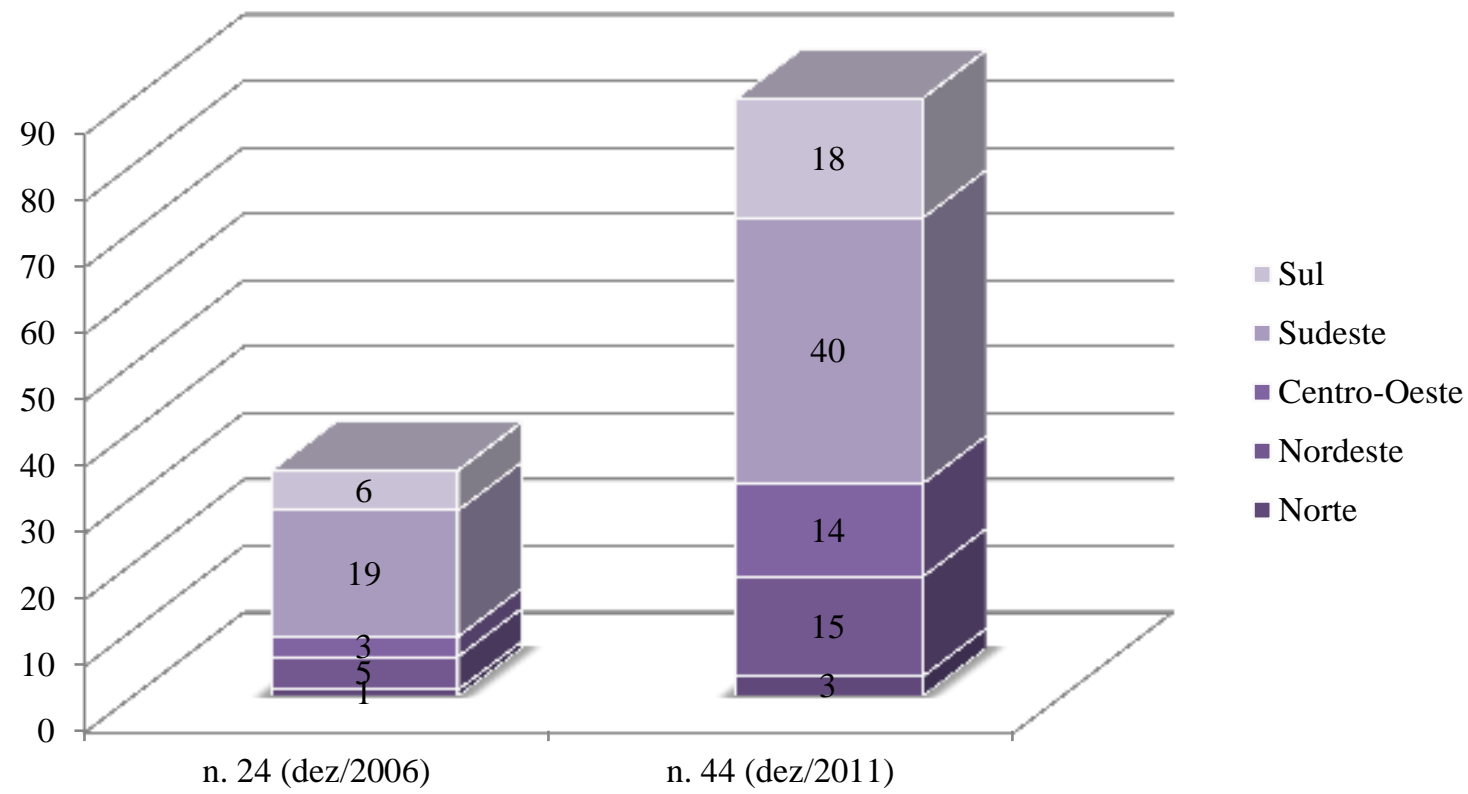

Figura 6 - Números absolutos de participantes do Conselho/Comissão Editorial da Revista HISTEDBR On-line, de acordo com os números 24 (dez/2006) e 44 (dez/2011).

Ainda assim, merece atenção o fato de algumas instituições possuírem muitos membros no Conselho/Comissão Editorial, em detrimento de outras. Destacam-se nesse sentido a UNICAMP (4 membros no n. 24 e 7 no n.44), a UFSCar (3 membros no n. 24 e 8 no n. 44) e a UESB (2 membros no n. 24 e 5 no n. 44).

É importante considerar que a diversidade relacionada ao pertencimento institucional e regional entre os membros do Conselho/Comissão Editorial é um dos elementos que assegura a constituição de uma comunidade discursiva (Swales, 1990) mais ampla e mais democrática. Essa diversidade permite que estejam representadas as diferenças vividas no mundo acadêmico brasileiro, como por exemplo, as diferentes formas de lidar com a escrita e as publicações nas Instituições de Ensino Superior públicas e privadas, ou a dificuldade de acesso ao circuito acadêmico de publicações e congressos entre habitantes da Região Norte do Brasil. Por outro lado, percebe-se a prevalência numérica de elementos das regiões Sul e Sudeste, de filiados a instituições federais de ensino superior, e uma representação numericamente elevada de determinadas instituições em detrimento de outras. Analisando as transformações sofridas ao longo dos anos, podese afirmar que a Revista HISTEDBR On-line avança em direção à composição de um corpo editorial - e de uma comunidade discursiva - cada vez mais ampla e diversificada.

\section{Autores}

O número 04 (out/2001), lançado na ocasião dos 15 anos de início e 10 de organização do Grupo HISTEDBR, nos ajuda a compreender o movimento relacionado à contribuição de autores para a revista analisada. O editorial desse número esclarece a respeito da origem do grupo, composto naquele momento por doutorandos e seus orientadores, e que se propunha a realizar estudos relacionados ao marxismo e educação. Na década de 1990, devido ao declínio do socialismo, o materialismo histórico foi deixado de lado na historiografia da educação, surgindo inovações metodológicas no campo. Nessa 
situação, o HISTEDBR optou por manter suas posições metodológicas iniciais, provocando com isso a oposição de diversos pesquisadores, em sua maior parte ligados ao grupo de trabalho da ANPEd. Tal posicionamento pode ter inibido a contribuição de muitos autores nos anos iniciais da Revista, já que o grupo caminhava em direção contrária a grande parte dos pesquisadores brasileiros. Talvez por isso, no número 24 (dez/2006, p. 2), Geraldo Inácio Filho afirme, no Editorial:

A Revista agradece a todos os colaboradores e mantém-se fiel ao propósito de
divulgar trabalhos de História da Educação, independentemente da filiação
teórica do articulista. Em que pese alguma tendência ter pruridos e até
preconceitos quanto a publicar neste periódico, nós não recusamos textos por
serem de orientação teórica diferente da dominante no Grupo.

Talvez até mesmo por constituir-se um ponto de tensão, a Revista sempre mantinha, na página inicial de todas as suas edições, um link para o índice de autores. Este índice considera todos os colaboradores, desde o início da revista; e até o número Especial de maio de 2010, indicava em quais edições há texto de cada autor.

Analisando o grupo HISTEDBR, pode-se perceber, de acordo com Swales (1990), algumas características que o classificam como comunidade discursiva: objetivos comuns, realizar estudos relacionados ao marxismo e educação; o uso de um léxico específico, composto a partir do materialismo histórico; e a existência de membros que detêm profundo conhecimento do discurso e conteúdos que circulam na comunidade, os professores orientadores. A criação da Revista viria completar este circuito, possibilitando uma forma reconhecida academicamente de comunicação e citação dos trabalhos entre os participantes do grupo.

Deve-se ainda considerar a existência de interesse pela diversificação e crescimento da comunidade discursiva, que pode ser expresso tanto na variedade de pertencimentos dos membros do corpo editorial, conforme anteriormente discutido, quanto na declaração de Inácio Filho a respeito da filiação teórica do articulista. Embora a Revista tenha sido criada como mecanismo de comunicação entre um grupo específico, ao longo do tempo tornou-se cada vez mais aberta, permitindo a colaboração de elementos que não partilham do objetivo inicial, e nem do mesmo léxico ou proposta metodológica. Para diversificar a comunidade discursiva, seria necessário aumentar a abrangência dos objetivos. Consequentemente, dever-se-ia também aumentar a abrangência dos mecanismos de comunicação, do léxico e dos membros especializados no conteúdo estudado.

A divulgação de um índice de autores pode ser considerada uma estratégia de representação da comunidade discursiva perante o circuito acadêmico. Inicialmente, o grupo HISTEDBR constituiu-se em um espaço de resistência acadêmica. Publicavam na Revista os membros desse grupo, e a lista de autores demonstrava quem eram aqueles que se posicionavam de forma contrária à monopolização metodológica da historiografia da educação brasileira. Posteriormente, nesse movimento de ampliação da comunidade discursiva, a divulgação dos autores que possuem textos publicados na Revista permite que se verifique não se tratar mais de um grupo tão fechado. Talvez por isso tenha sido suspensa a indicação de em quais volumes é possível encontrar textos de cada autor, já que assim é possível perceber que um determinado grupo de autores publicou bem mais que os outros. Considerando a lista de autores do número Especial (maio/2010), percebe-se que dentre os professores orientadores que faziam parte do grupo HISTEDBR na época de resistência metodológica, há alguns que chegam a ter mais de dez artigos publicados no periódico, tanto individuais quanto com orientandos. 
A lista de autores dos números 24 (dez/2006), Especial (maio/2010) e 44 (dez/2011) contam com 390, 686 e 816 autores, respectivamente. É possível perceber, considerando apenas as duas revistas mais antigas, que aproximadamente $24 \%$ dos autores possuía mais de uma publicação na Revista. O número máximo alcançado de publicações por autor foi catorze artigos, verificado na Edição Especial (maio/2010). Esse número foi atingido por uma professora orientadora que escreveu tanto sozinha quanto em parceria com orientandos. Tais dados levam a questionar se efetivamente a Revista HISTEDBR On-line tem conseguido aumentar a abrangência de sua comunidade discursiva. Embora tenha havido um aumento numérico significativo, a progressão de autores com mais de uma publicação tem acompanhado na mesma proporção. Esse dado aponta para um crescimento na comunidade discursiva, mas também para sua estabilização, com sujeitos que publicam recorrentemente.

\section{Linhas de pesquisa}

Ao longo dos anos, as linhas de pesquisa da HISTEDBR On-line foram sofrendo transformações. O número 1 da publicação, de setembro de 2000, descrevia suas linhas de pesquisa como: Historiografia e Concepções Teórico-Metodológicas da História da Educação; Estudos Temáticos e História Regional da Educação; Estudos HistóricoBiográficos da Educação. Em dezembro de 2006, no número 24, a seção Normas Editoriais apresentava estas três linhas gerais de pesquisa: Historiografia e questões teórico-metodológicas da história da educação; história das políticas educacionais no Brasil; história das instituições escolares no Brasil. A última edição de 2011, de número 44, é mais abrangente em seus critérios, ao situar o tema de suas publicações na área de história da educação.

Embora no início da publicação houvesse uma orientação quanto a três linhas de pesquisa, a análise dos números 3 e 4 do periódico, de julho e setembro de 2001, respectivamente, nos levam a perceber uma predominância de temas relacionados à linha Estudos Temáticos e História Regional da Educação.

Tabela 1 - Artigos da HISTEDBR On-line, n. 3, jul./2001.

\begin{tabular}{|ll|}
\hline \multicolumn{2}{|c|}{ TÍTULO DO ARTIGO } \\
$\begin{array}{|ll|}\text { Educação no Brasil: concepções e desafios para o século } \\
\text { XXI }\end{array}$ & Dermeval Saviani \\
\hline História da Educação e Política Educacional & Dermeval Saviani \\
\hline $\begin{array}{l}\text { O Iluminismo de Kant e o Positivismo de Durkheim em } \\
\text { relação à Educação }\end{array}$ & Alzide L. Andreotti \\
\hline $\begin{array}{l}\text { A concepção pedagógica de Jorge Benci para os } \\
\text { escravizados coloniais }\end{array}$ & Ana Palmira Bittencourt Santos Casimiro \\
\hline
\end{tabular}

Tabela 2 - Artigos da HISTEDBR On-line, n. 4, set/2001.

\begin{tabular}{|ll|}
\hline \multicolumn{1}{|c|}{ TÍTULO DO ARTIGO } & \multicolumn{1}{c|}{ AUTOR } \\
\hline 15 anos de HISTEDBR: histórico e situação atual & Dermeval Saviani; José Claudinei Lombardi \\
\hline $\begin{array}{l}\text { A Sociedade do Conhecimento no Conhecimento dos } \\
\text { Educadores }\end{array}$ & Ligia Helena Nagel \\
\hline 15 anos de HISTEDBR & Gilberto Luiz Alves \\
\hline $\begin{array}{l}\text { Os "Homens de Negócio" e a política educacional do } \\
\text { MEC }\end{array}$ & Galdêncio Frigotto \\
\hline $\begin{array}{l}\text { "Século XX cambalache, problemático e febril" ou "que } \\
\text { falta de respeito e atropelo à razão" }\end{array}$ & Nilda Alves \\
\hline
\end{tabular}


Observando a Tabela 1 e a Tabela 2, percebe-se que os nove artigos publicados nestes dois números do periódico, apenas um se adequaria à linha Historiografia e Concepções Teórico-Metodológicas da História da Educação, e nenhum à linha Estudos HistóricoBiográficos da Educação. Percebe-se ainda uma tendência nas publicações em tratar de assuntos que se relacionam mais diretamente com o século XX que com os anteriores: cinco $^{3}$ deles $(62,5 \%)$ relacionam-se com temas deste período, principalmente a seu terço final. Temas relacionados à política educacional apareceram ao menos uma vez em cada número analisado, e nenhum artigo tratou diretamente de instituições educacionais.

O número 24 , de dezembro de 2006 , teve um aumento considerável no número de artigos: doze ao todo. As linhas de pesquisa foram alteradas, mantendo-se a linha Historiografia e questões teórico-metodológicas da história da educação, e alterando as duas restantes para história das políticas educacionais no Brasil e história das instituições escolares no Brasil. É notório que as linhas consideraram uma tendência que se explicitava já nos primeiros números, valorizando a presença de temas relacionados às políticas educacionais e criando a possiblidade de publicações sobre instituições escolares - assunto que ficou esquecido nos números anteriormente analisados.

Tabela 3 - Artigos da HISTEDBR On-line, n. 24, dez/2006.

\begin{tabular}{|c|c|}
\hline TÍTULO DO ARTIGO & AUTOR \\
\hline $\begin{array}{l}\text { Manifestações da ação de particulares e de professores de } \\
\text { primeiras letras em prol da escolarização em São Paulo no } \\
\text { final do século XIX }\end{array}$ & Analete Regina Schelbauer \\
\hline $\begin{array}{l}\text { As manifestações do positivismo e do liberalismo no } \\
\text { pensamento educacional da imprensa de Uberabinha - MG } \\
(1907-1942)\end{array}$ & $\begin{array}{l}\text { Carlos Henrique de Carvalho; Luciana Beatriz } \\
\text { de Oliveira Bar de Carvalho }\end{array}$ \\
\hline $\begin{array}{l}\text { Docentes na escola de aprendizes artífices do Pará: } \\
\text { diacronia dessa atuação }\end{array}$ & Guedes \\
\hline $\begin{array}{l}\text { Lyceu de Goyaz: equiparação ao Colégio de Pedro II e } \\
\text { inclusão no universo do ensino secundário brasileiro }\end{array}$ & Fernanda Barros \\
\hline A humanidade, a natureza e o trabalho & Carlos Lucena \\
\hline $\begin{array}{l}\text { Tópicos em educação nas cartas de Manuel da Nóbrega: } \\
\text { entre práticas e representações (1549-1559) }\end{array}$ & Marcos Roberto de Faria \\
\hline $\begin{array}{l}\text { As congregações católicas e a disseminação de escolas } \\
\text { femininas no Triângulo Mineiro e Alto Paranaíba }\end{array}$ & $\begin{array}{l}\text { Michelle Pereira da Silva Rossi; Geraldo } \\
\text { Inácio Filho }\end{array}$ \\
\hline $\begin{array}{l}\text { O debate sobre as universidades populares na imprensa } \\
\text { portuguesa de educação e ensino. O exemplo de "A vida } \\
\text { portuguesa" (1912-1915) }\end{array}$ & Joaquim Pintassilgo \\
\hline El movimento pedagogico em Colombia & Alfonso Tamayo Valencia \\
\hline $\begin{array}{l}\text { Patrimônio Cultural, história da educação e formação } \\
\text { continuada de professores }\end{array}$ & $\begin{array}{l}\text { Maria de Fátima Ramos de Almeida; Sandra } \\
\text { Cristina Fagundes de Lima }\end{array}$ \\
\hline $\begin{array}{l}\text { A educação moral e cívica - doutrina, disciplina e prática } \\
\text { educativa }\end{array}$ & Vanessa Kern de Abreu; Geraldo Inácio Filho \\
\hline $\begin{array}{l}\text { Estado e brasileiros na escolarização portuguesa do século } \\
\text { XIX }\end{array}$ & $\begin{array}{llll}\text { Wenceslau } & \text { Gonçalves } & \text { Neto; } & \text { Justino } \\
\text { Magalhães } & & & \end{array}$ \\
\hline
\end{tabular}

A partir dos títulos acima, pode-se perceber que as linhas de pesquisa têm sido interpretadas como orientações aos autores, e não limites rígidos às contribuições. Embora as linhas explicitem claramente que as pesquisas devem tratar de temas relacionados ao Brasil - exceto na linha de historiografia, podemos perceber a contribuição de um autor estrangeiro, tratando do movimento pedagógico na Colômbia. Há ainda um artigo que trata 
do Brasil, mas na escolarização portuguesa. Artigos que discutem a educação na e através da literatura periódica e que, portanto não estão previstos nas linhas de pesquisa, também foram publicados. Persiste a tendência da publicação de artigos que tratam de temas relacionados ao século XX: dos doze artigos, dez correspondem a esse recorte temporal, um ao século XIX e um ao século XVI. A tendência de publicação de artigos que abordam temas relacionados à área da educação é citada no Editorial do número 24 (dez/2006), pelo organizador do número, Geraldo Inácio Filho:

\footnotetext{
Recentemente, o professor Paulo Ghirardelli Jr propôs que a abundância de textos na área da educação (ou seria História da Educação?) refletiria uma crise profunda. Creio que tem razão. Talvez essa proliferação de textos e de produção seja reflexo de uma crise que, por sua vez, demonstre uma necessidade de (a área) ser vista, de ser percebida. (p. 1)
}

Assim, a HISTEDBR On-line prosseguiu publicando textos que abordam recortes temporais cada vez mais recentes.

O número 44, de dezembro de 2011, reflete a maleabilidade nas linhas de pesquisa da revista, ao estabelecer como critério que sejam publicações na área de história da educação. A Tabela 4 indica os títulos e autores deste número:

Tabela 4 - Artigos da HISTEDBR On-line, n. 44, dez/2011

\begin{tabular}{|c|c|}
\hline TÍTULO DO ARTIGO & IUTOR \\
\hline La Educación superior privada en Brasil & Claudio Rama \\
\hline $\begin{array}{l}\text { Por uma educação profissional de tecnólogos a partir dos } \\
\text { conceitos de omnilateralidade e politecnia }\end{array}$ & $\begin{array}{l}\text { Luiz Alberto de Azevedo; Ari Paulo } \\
\text { Jantsch }\end{array}$ \\
\hline A relação trabalho e educação na pedagogia da alternância & $\begin{array}{l}\text { Glademir Alves Trindade e Célia Regina } \\
\text { Vendramini }\end{array}$ \\
\hline $\begin{array}{l}\text { Formação e atuação do professor na sociedade } \\
\text { contemporânea: implicações e possibilidades }\end{array}$ & $\begin{array}{l}\text { Marta Regina Furlan Oliveira e Adriana } \\
\text { Regina de Jesus Santos }\end{array}$ \\
\hline $\begin{array}{l}\text { as tecnologias gerenciais para } \\
\text { ão }\end{array}$ & Rafael Rodrigo Mueller \\
\hline $\begin{array}{l}\text { Educação no campo e trabalho: um estudo das escolas } \\
\text { municipais rurais de Uberlândia - MG }\end{array}$ & $\begin{array}{l}\text { Ana Cecília Oliveira Silva; Fabiane } \\
\text { Santana Previtali }\end{array}$ \\
\hline $\begin{array}{l}\text { Educação e economia: a (re) construção histórica a partir do } \\
\text { pós-guerra }\end{array}$ & $\begin{array}{l}\text { Eduard Angelo Bendrath; } \\
\text { Albuquerque Gomes }\end{array}$ \\
\hline $\begin{array}{l}\text { A instituição da inspetoria técnica no âmbito do projeto de } \\
\text { modernização da educação implementado com a reforma de } \\
1906 \text { em Minas Gerais: estratégia de modelização do ensino }\end{array}$ & Rogéria Moreira Rezende Isobe \\
\hline $\begin{array}{l}\text { Docência, Gestão e Conhecimento: conceitos articuladores do } \\
\text { novo perfil do pedagogo instituído pela Resolução CNE/CP } \\
\text { N. } 01 / 2006\end{array}$ & a \\
\hline ações afirmativas & Lima \\
\hline $\begin{array}{l}\text { A formação superior nos romances Memórias Póstumas de } \\
\text { Brás Cubas, de Machado de Assis, e os Irmãos Karamazóvi, } \\
\text { de Fiódor Dostoiéwski }\end{array}$ & $\begin{array}{l}\text { Luís Henrique de Freitas Calabresi } \\
\text { Marisa Bittar }\end{array}$ \\
\hline $\begin{array}{l}\text { Ensino superior e política educacion } \\
\text { superior no Sudoeste do estado do Par }\end{array}$ & nena \\
\hline $\begin{array}{l}\text { Sociedade, ciência e educação: abordagens sobre } \\
\text { conhecimento pedagógico na teorização de Anísio Teixeira }\end{array}$ & 吾 \\
\hline $\begin{array}{l}\text { Educação ao longo da vida nas políticas educacionais e a } \\
\text { pretendida ausência da história }\end{array}$ & $\hat{\hat{n}}$ \\
\hline $\begin{array}{l}\text { A proposta de Lourenço Filho para a educação de crianças de } \\
0 \text { a } 6 \text { anos }\end{array}$ & $\begin{array}{l}\text { Mara Cecília Rafael; Ângela Mara de } \\
\text { Barros Lara }\end{array}$ \\
\hline Política educacional, justiça distributiva e equidade: & \\
\hline
\end{tabular}


considerações sobre as políticas compensatórias para a

educação

O proformação e seu modelo de educação à distância $\quad$ Raquel de Almeida Moraes

Educação integral, ensino integral e tempo no pensamento de Nailda Marinho da Silva Bonato, Lígia

Rui Barbosa

Martha Coimbra da Costa Coelho, Janaína

Specht da Silva Menezes

O intelectual educador Manoel Bonfim e a interpretação do Sônia Câmara; Marcela Cockell

Brasil e da América Latina

Neste número, persiste a tendência de um recorte temporal mais próximo da contemporaneidade: dos dezenove artigos publicados, dez tratam de assuntos a partir da década de 1990, três de assuntos em um limite de seis décadas estendendo-se até a atualidade, três referem-se à primeira metade do século XX, dois ao final do XIX estendendo-se pelo XX, e apenas um trata do século XIX.

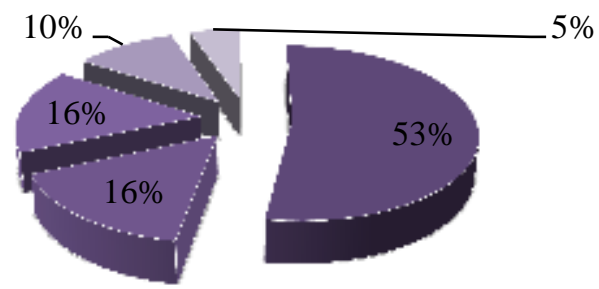

\author{
- A partir da década de 1990 \\ - A partir da década de 1950 \\ - Primeira metade do século XX \\ - Final do século XIX e início do XX \\ Século XIX
}

Figura 7 - Percentual de artigos por recorte temporal na HISTEDBR On-line, n. 44, dez./2011

É sintomático que o Editorial deste último número apresente o grupo que o organizou (Núcleo de Estudos em Educação Brasileira - NEB, UNIRIO) enfatizando a produção do grupo na área de História da Educação. Isto pode ter sido uma ressalva dos organizadores, procurando demonstrar que a publicação de artigos que, em grande parte, tratam de temas contemporâneos, não reflete uma escolha particular, e sim uma tendência da revista em questão.

Considerando o movimento dos critérios de publicação nas revistas anteriores, e as ponderações contidas nos editoriais, é possível perceber que a revista HISTEDBR On-line está seguindo um movimento de transformação em uma revista de educação mais generalista, e não apenas de história da educação. Esta tendência manifesta-se também através da observação dos títulos dos artigos publicados: nos artigos do número 24, observa-se com mais frequência a referência ao recorte temporal já no título do artigo. Esta é uma prática bastante comum nas publicações do campo de história da educação. Já no número 44, esta referência não é feita na maioria das vezes, e em alguns casos sequer aparece no resumo do artigo.

É possível que a empreitada de diversificação da comunidade discursiva da Revista tenha encontrado severos obstáculos, relacionados à introdução de outros autores da área da História da Educação. Tornar a revista mais aberta a outras áreas da Educação cria maiores possibilidades para esta empreitada.

\title{
Normas para publicação
}

Os tipos de publicação permitidos pela HISTEDBR On-line sofreram algumas variações durante os últimos anos. Essas variações expressam-se tanto no tipo de 
publicação quanto nas normas de cada uma delas. No número 14 (jun/2004) ${ }^{4}$, são permitidas contribuições no formato de artigos, comunicações, resenhas, documentos e comentários. Nos números 24 (dez/2006) e 44 (dez/2011), são permitidos artigos, resenhas, documentos, resumos de teses e dissertações, e imagens de eventos promovidos pela HISTEDBR. O número de páginas permitido por contribuição varia ao longo destes últimos anos, como pode ser observado na Tabela 5:

Tabela 5 - Variações de tipos e extensão das publicações da HISTEDBR On-line

\begin{tabular}{|lccc|}
\hline Artigo & $\mathbf{1 4}$ (jun/2004) & 24 (dez/2006) & $\mathbf{4 4}$ (dez/2011) \\
\hline Comunicação & $1-6$ páginas & Máximo 25 páginas & $10-25$ páginas \\
\hline Resenha & $1-6$ páginas & - & - \\
\hline Documentos & $2-4$ páginas & $\begin{array}{c}10 \text { mil caracteres } \\
\text { com espaço }\end{array}$ & $3-5$ páginas \\
\hline Comentário & $1-6$ páginas & Não determina & Máximo 3 páginas \\
\hline Resumo de tese ou dissertação & $4-6$ páginas & - & - \\
\hline Imagens & $2-8$ páginas & Máximo 10 linhas & $\begin{array}{c}\text { 1 página (300 a 500 } \\
\text { palavras) }\end{array}$ \\
\hline
\end{tabular}

Como se pode observar, a extensão do artigo aumentou consideravelmente ao longo das edições da revista: o número mínimo de páginas ficou 10 vezes maior, e o número máximo pouco mais de quatro vezes. A bem dizer, todas as modalidades de publicação ficaram maiores ao longo do tempo, com exceção do resumo de tese ou dissertação. Esta sofreu uma redução radical em sua extensão entre 2004 e 2006: de 8 páginas para 10 linhas ao máximo, aumentando para 1 página na última edição de 2011. É perceptível que as normas do número 44 procuram esclarecer e limitar os tipos de publicações cujas normas não estavam ainda definidas no número 24 , como os documentos e imagens. Também é possível observar alterações nos tipos de publicações permitidas na revista: as comunicações deixaram de ser uma modalidade válida, assim como os comentários. Além disso, passaram a ser aceitas imagens de eventos promovidos pelo grupo HISTEDBR.

Acerca da veiculação de imagens pela Revista, é interessante considerar que o grupo HISTEDBR constituiu-se um movimento de resistência dentro da historiografia da educação brasileira, sofrendo oposição por causa disso (Carvalho, 2000). A veiculação de imagens dos eventos promovidos pelo grupo - e de seus participantes, consequentemente auxilia na construção de representações (cf. Chartier, 1990) a respeito do grupo. Embora seu acesso tenha sido restrito em alguns círculos acadêmicos, conforme denuncia a fala de Inácio Filho na edição de número 24 (dez/2006), a veiculação de fotos demonstra que o grupo existe, está em funcionamento, e que os seus participantes não temem em ser vistos e identificados como tais.

Considerando que na edição de número 14 (jun/2004) só eram permitidas contribuições de membros do grupo HISTEDBR, pode-se afirmar que a Revista constituíase um evento de letramento acadêmico (FISCHER, 2006), que possibilitava o desenvolvimento de identidades profissionais coerentes com o pertencimento do grupo - e diferentes das desenvolvidas pelos orientadores e orientandos ligados ao grupo da ANPED. Esta prática também concorda com o modelo da socialização acadêmica conforme descrito por Lea e Street (1998), pois os alunos do grupo são aculturados em diversas formas de gêneros e discursos, que possibilitam seu êxito caso tenham a necessidade de publicar fora do grupo, inserindo-se em outras comunidades discursivas. Cabe ressaltar que essa demanda se torna mais forte a partir da criação da Sociedade Brasileira de História da Educação - SBHE, e dos eventos e revistas produzidos por ela. 
Por outro lado, é perceptível que estas normas foram alteradas ao longo do tempo, coincidindo com as mudanças relacionadas à maior abertura da comunidade discursiva composta na e pela Revista HISTEDBR On-line. Pode-se dizer, portanto, que o modelo de produção textual adotado pelo periódico transformou-se no que é chamado por Lea e Street (1998) de Letramentos Acadêmicos. Ao aceitar contribuições com orientações teóricas diferentes daquelas adotadas pelo grupo, a Revista está aceitando que a produção do conhecimento em História da Educação pode ser diferente, de acordo não apenas com a vinculação epistemológica do autor, mas com a vinculação social, institucional, e as identidades a partir daí produzidas.

Quanto aos artigos, é interessante observar que os números 24 (dez/2006) e 44 (dez/2009) permitiam, excepcionalmente, a publicação de artigos não inéditos, de autores brasileiros ou estrangeiros - desde que tivessem sido anteriormente publicados em livros e periódicos de circulação restrita no Brasil. Embora o número 14 (jun/2004) não fizesse essa mesma concessão, permitia, aos autores de texto inédito, enviá-lo simultaneamente para até três revistas virtuais. Esta prática concorda com o uso inicial da Revista como um ambiente de socialização acadêmica para os alunos, já que teriam a oportunidade de fazê-lo circular entre sua comunidade discursiva, enquanto ele era avaliado para a inserção em outra comunidade. Mesmo que o texto não fosse aprovado no outro periódico, os apontamentos realizados pelo(s) avaliador(es) externo(s) e pela comunidade discursiva da Revista HISTEDBR On-line ofereceriam ao aluno a possibilidade de aprender mais sobre como obter êxito na publicação de seus textos.

Acerca da forma de construção dos artigos e sua normatização, em junho/2004, a HISTEDBR On-line se reservava o direito de realizar nos artigos alterações editoriais não substanciais (reparagrafações, correções gramaticais, adequações estilísticas $e$ editoriais). Já no número 24 (dez/2006), caso os pareceristas ou a Comissão Editorial sugerissem alguma modificação de estrutura ou conteúdo no texto, esta só seria incorporada mediante concordância dos autores. No número 44 (dez/2011), existe a advertência quanto à possibilidade de os artigos virem a sofrer os mesmos tipos de alterações editoriais - sem mencionar a autorização por parte dos autores para isso.

No número 14 (jun/2004), a estrutura de construção dos artigos era bem mais rígida. Nesse número, é estabelecido que os textos devem ter introdução, desenvolvimento e conclusão, não necessariamente sofrendo sub divisões. As ilustrações (tabelas, gráficos, desenhos, mapas e fotografias) deveriam ser inseridas como anexos do texto. Identificação do autor e título do artigo deveria vir em uma folha separada. Há uma seção explicativa para notas, citações e referências bibliográficas, inclusive com exemplos de referências para cada tipo de documento. Esta rigidez reflete a necessidade do grupo de ensinar os alunos a publicar com qualidade, tanto na organização quanto na normatização do texto.

Em dez/2006 e dez/2011, as advertências com relação ao formato do texto são diferentes: passa-se a exigir título e identificação do autor e seu vínculo institucional na primeira página do artigo. Este modelo coopera à prática dos Letramentos Acadêmicos, já que permite que o texto seja avaliado de acordo com seu contexto social e epistemológico de produção. Além das mudanças na identificação, passam a ser exigidos um resumo e palavras chave em português, seguido pelo título do artigo em inglês, abstract e key-words. Estas transformações apontam para o movimento de ampliação da comunidade discursiva - o uso de título, resumo e palavras chave em outro idioma indica que se espera que haja leitores de outra origem linguística. Nas duas edições existem modelos de cabeçalho para os artigos. Há um maior investimento em normas referentes à formatação que à construção do artigo: passam a constar orientações quanto ao tamanho e tipo de fonte, espaçamento, realces. Em dez/2011, já constam normas quanto ao tamanho do papel, margens, 
alinhamento do texto e recuos. Ilustrações e gráficos podem fazer parte do texto, desde que a fonte seja devidamente mencionada. As referências bibliográficas, notas e citações devem seguir as normas da ABNT.

As resenhas são definidas nos números 14 (jun/2004) e 24 (dez/2006) como comentário crítico de livros elou teses. No número mais antigo, é enfatizada a necessidade de a resenha identificar a obra comentada, ressaltando cada item da referência bibliográfica. Nos números 24 (dez/2006) e 44 (dez/2011), ressalta-se apenas que é indispensável a indicação da referência bibliográfica da obra comentada. O número mais recente traz um modelo de cabeçalho para as resenhas em sua seção de Normas Editoriais, e explicita a permissão para que o autor atribua um título à resenha - prática que não ocorreu no número 14, mas já ocorria no número 24.

A seção Documentos sofreu alterações significativas: em jun/2004, as publicações nessa seção eram definidas como levantamento crítico de um tema, a partir da bibliografia disponível. Em dez/2006, a descrição informa que Nessa seção são divulgados textos, bem como documentos (leis, pareceres, normalizações), emanados de órgãos governamentais $e$ que abordem questões de interesse para a área educacional. Na edição mais recente, esta descrição é mantida, ressaltando-se a necessidade de informar o título, ano e fonte do documento. $\mathrm{O}$ apresentador deverá também se identificar, e fazer uma breve apresentação do documento.

Os resumos de teses ou dissertações devem conter, em todas as edições, os seguintes elementos: título, autor, instituição, orientador e um breve resumo dos capítulos. O resumo sempre é feito pelo autor do trabalho. O número 44 (dez/2011) torna opcional citar o nome do orientador, mas acrescenta como essencial citar o ano de defesa, além da expressão "Resumo de Tese de Doutorado" ou "Resumo de Dissertação de Mestrado". Tanto o número 24 (dez/2006) quanto o 44 (dez/2011) trazem modelos do cabeçalho para resumo.

A partir dos números analisados da revista HISTEDBR On-line, percebe-se um movimento em direção à maior normatização na formatação, e maior liberdade na forma de construção dos textos. Busca-se uma uniformização na aparência, mas valoriza-se a diversidade na produção do conhecimento. Também se deve ressaltar o investimento na melhoria da aparência e acessibilidade dos textos: até o número 12 (dez/2003), o acesso aos textos era disponibilizado a partir de páginas $h t m$, mudando para arquivos em $p d f$ a partir do número 13 (mar/2004). Esta mudança aperfeiçoou a visualização dos textos, bem como as possibilidades de salvar o arquivo para utilização posterior, ou mesmo imprimi-lo. A partir do número 14 (jun/2004), passou-se a exibir o link para os números anteriores. Porém a mudança na interface da revista, ocorrida a partir do número 28 (dez/2007), trouxe a dificuldade do retorno à página inicial de cada edição, já que o link foi retirado.

\section{Tipos e quantidades de publicações}

Conforme dito anteriormente, a Revista HISTEDBR On-line circula ininterruptamente desde o ano de 2000, contando inclusive com algumas edições especiais. Ao longo desse tempo, a presença e a variedade de gêneros de publicação sofreram algumas alterações. Podemos observar estas variações na tabela abaixo:

Tabela 6 - Presença e variedade de gêneros na Revista HISTEDBR On-line, entre os números 01 e 44

\begin{tabular}{|c|c|c|c|c|c|c|c|}
\hline Edição & Artigos & Comunicações & Resenhas & Documentos & Comentário & $\begin{array}{l}\text { Resumo de } \\
\text { tese ou } \\
\text { dissertação }\end{array}$ & Imagens \\
\hline 01 Setembro/2000 & 2 & f.s. ${ }^{5}$ & f.s. & f.s. & f.s. & f.s. & f.s. \\
\hline 03 Julho/2001 & 4 & - & 1 & 1 & - & f.s. & - \\
\hline
\end{tabular}




\begin{tabular}{|c|c|c|c|c|c|c|c|}
\hline 04 Outubro/2001 & 5 & - & 2 & f.s. & f.s. & f.s. & - \\
\hline 07 Julho/2002 & 1 & - & 1 & 1 & f.s. & f.s. & - \\
\hline 09 Março/2003 & 23 & - & 3 & 2 & - & f.s. & - \\
\hline 10 Junho/2003 & 18 & - & 2 & 1 & - & 8 & - \\
\hline 11 Setembro/2003 & 29 & - & 1 & 1 & - & 11 & $1(22)$ \\
\hline 14 Junho/2004 & 12 & - & 1 & - & - & 4 & $1(8)$ \\
\hline 15 Setembro/2004 & 19 & - & 1 & 2 & - & 1 & - \\
\hline 16 Dezembro/2004 & 10 & - & 2 & - & - & 2 & 5 \\
\hline 17 Março/2005 & 11 & - & 2 & 1 & - & 10 & - \\
\hline 18 Junho/2005 & 18 & - & 3 & 3 & - & 8 & 2 \\
\hline 19 Setembro/2005 & 10 & - & 2 & - & - & 5 & - \\
\hline 23 Setembro/2006 & 12 & - & 5 & 1 & - & 2 & - \\
\hline 24 Dezembro/2006 & 12 & - & 1 & - & - & 3 & - \\
\hline 25 Março/2007 & 15 & - & 5 & 1 & - & 11 & - \\
\hline 26 Junho/2007 & 12 & - & 2 & 1 & - & 2 & - \\
\hline 27 Setembro/2007 & 20 & - & 2 & 1 & - & 7 & 1 \\
\hline 28 Dezembro/2007 & 19 & - & 2 & 2 & - & 4 & $1(6)$ \\
\hline 29 Março/2008 & 18 & - & 3 & 1 & - & 4 & - \\
\hline 30 Junho/2008 & 18 & - & 3 & 1 & - & 6 & - \\
\hline 31 Setembro/2008 & 14 & - & 3 & 1 & - & 3 & - \\
\hline 32 Dezembro/2008 & 18 & - & 5 & 3 & - & 4 & - \\
\hline 33 Março/2009 & 16 & - & 3 & 2 & - & 4 & - \\
\hline 40 Dezembro/2010 & 18 & - & 1 & 2 & - & 6 & - \\
\hline 41 Março/2011 & 19 & - & 1 & 1 & - & 8 & - \\
\hline Especial Abril/2011 & 24 & - & 1 & 2 & - & 2 & - \\
\hline 42 Junho/2011 & 18 & - & 1 & 1 & - & 6 & - \\
\hline 43 Setembro/2011 & 20 & - & 1 & 2 & - & 2 & - \\
\hline Especial Outubro/2011 & 17 & - & 1 & 1 & - & 1 & - \\
\hline 44 Dezembro/2011 & 19 & - & 3 & 1 & - & 5 & \\
\hline TOTAL $^{6}$ & 704 & - & 120 & 61 & - & 174 & 14 \\
\hline
\end{tabular}

Como se pode observar, embora inicialmente houvesse normas para a publicação de Comunicação e Comentários, estas duas modalidades nunca foram utilizadas. A publicação de imagens, embora seja possível até o número 44 (dez/2011), ocorreu poucas vezes ao longo da publicação da revista, mais precisamente nos números 11, 14, 16, 18, 21, 27 e 28. Foi considerado, nas somatórias, o número de coletâneas de imagens, e não o assunto ou número total das mesmas. Como os números 11, 14 e 28 não tiveram as imagens organizadas por coletânea, o total de imagens foi considerado como uma unidade, estando entre parênteses na tabela o número de fotos em cada um deles. Cabe ressaltar que nem todas essas imagens correspondem a eventos do Grupo HISTEDBR. Em algumas edições, publicaram-se também coletâneas de imagens históricas.

Observou-se, na revista estudada, que as formas de publicação mais numerosas são o artigo (704), seguido pelo resumo de teses ou dissertações (174), as resenhas (120), e em último lugar os documentos (61). A única modalidade de publicação que está presente em todos os números da revista é o artigo, variando numericamente entre 1 e 29 publicações deste tipo na mesma edição. O número máximo de resenhas publicadas por edição foi 12 (out/2002 e mar/2006), e o maior número de resumo de teses ou dissertações foi 11 (set/2003, mar/2006 e mar/2007). 
Destaca-se, por sua forma de organização, o número 08 (out/2002). Por se tratar de uma edição comemorativa pelos dois anos da edição, o formato padrão de organização foi modificado, publicando-se um artigo, um documento, 12 resenhas, 70 fichas bibliográficas e uma seção de bibliografia, que procura catalogar as fontes levantadas ao longo desses dois anos. Nenhum outro número especial teve alterações de organização como este, mantendo o mesmo formato das edições regulares.

Cabe ressaltar que, de acordo com Carvalho (2000), a organização de um catálogo de fontes, ao lado da oposição metodológica, foi uma das razões de conflito entre o HISTEDBR e o grupo de trabalho de História da Educação da ANPEd. O conflito foi amenizado após a criação da Sociedade Brasileira de História da Educação - SBHE, em 1999. Assim, este catálogo foi publicado na Revista, em 2002.

O número de artigos publicados tem variado muito ao longo da história da revista. Elaborando um gráfico a respeito da variação numérica na quantidade de artigos publicados pela HISTEDBR On-line, temos o seguinte resultado:

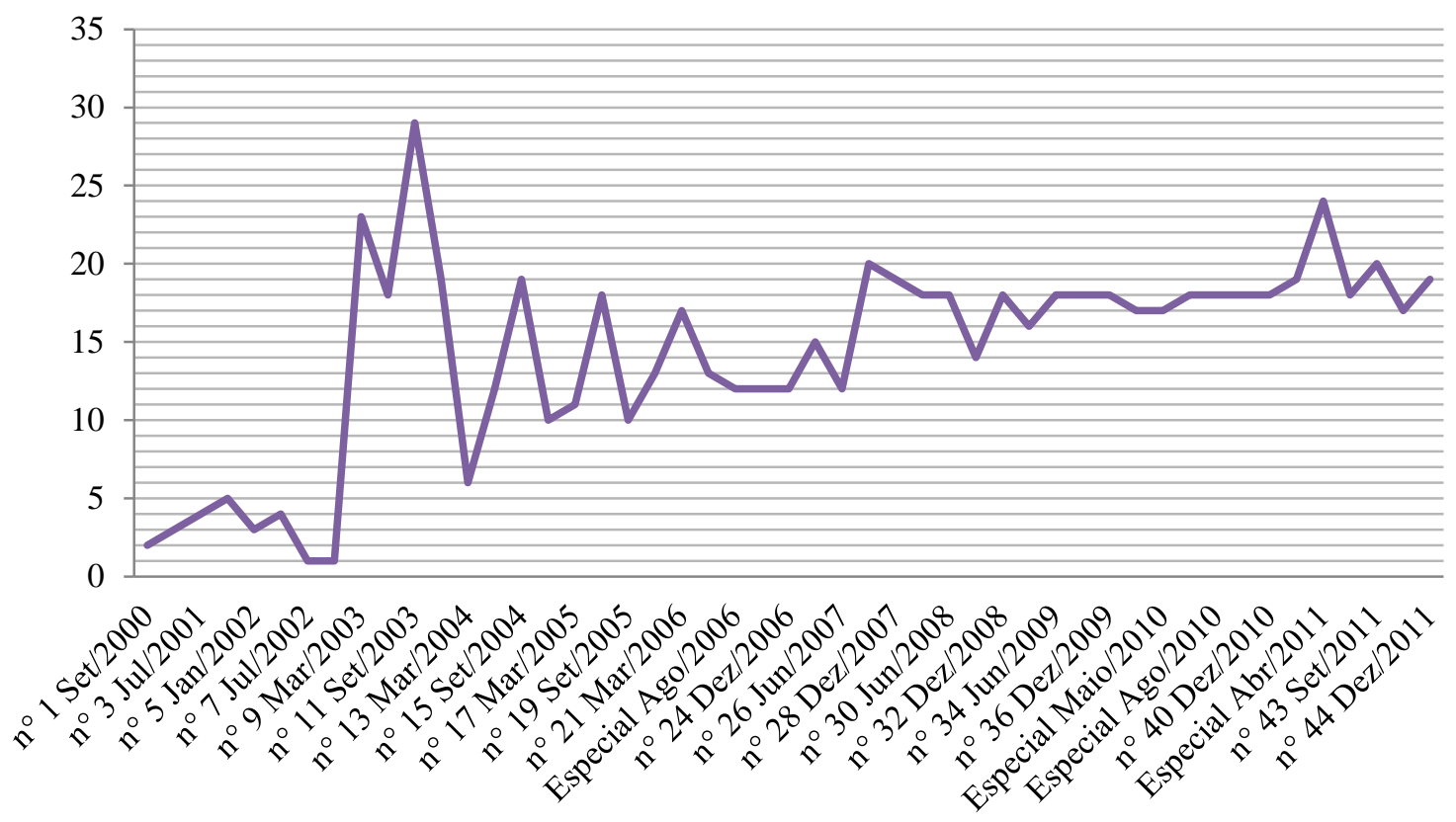

Figura 8 - Oscilação numérica na quantidade de artigos publicados na Revista HISTEDBR On-line, entre os números 01 e 44

Nas edições mais antigas, a variação numérica neste tipo de publicação era maior e mais frequente, tendo a oscilação diminuído desde o segundo semestre de 2007. A partir de então, há uma média de 17,9 artigos por edição. Não há, nas normas, nenhuma especificação quanto ao número de artigos por edição. O número de artigos nos números especiais pouco varia em relação aos números publicados nas edições regulares.

A partir da análise numérica dos resumos de teses e dissertações publicados na Revista HISTEDBR On-line, percebe-se que o periódico constitui-se um espaço importante para divulgação de trabalhos de pós-graduação. Assim como no caso dos artigos, percebe-se uma forte oscilação no número de resumos publicados por edição da revista. Apesar das oscilações, é perceptível uma tendência à queda no número de publicações nesta categoria. Uma hipótese que explicaria este fato seria a possibilidade de que os egressos da pós-graduação estejam preferindo adaptar seus trabalhos no formato de artigo, do que publicar o resumo do mesmo. Esta tendência pode estar diretamente 
relacionada à maior valorização do gênero artigo em detrimento ao gênero resumo no círculo acadêmico - e nos concursos para docentes, diga-se de passagem.

Quanto às resenhas, inicialmente publicavam-se análises de teses de doutoramento (número 03, jul/2001), capítulos de livros (número 04, out/2001) e livros completos (número 06, abr/2002). É possível que a permissão de publicação da resenha de capítulos de livros seja relacionada à utilização crítica de textos para estudo entre o grupo, já que inicialmente a publicação tinha um caráter bastante internalizador. No número 14 (jun/2004), as normas já esclareciam que as resenhas só poderiam contemplar livros completos e teses de doutoramento. O número 24 (dez/2006) mantém esta orientação. É possível que as normas tenham sido alteradas para seguir a tendência dos demais periódicos. Ainda assim, era possível resenhar teses de doutorado, fazendo com que trabalhos daquela ou mesmo de outra comunidade discursiva fossem analisados, o que permitiria o aprendizado das características e exigências dessa modalidade entre os membros do grupo. O número 44 (dez/2011), porém, limita a resenha a livros, excetuando essa possibilidade.

As datas de edição das obras resenhadas variaram ao longo das edições. No número 44 (dez/2011), são resenhados livros com no máximo dois anos de publicação. No número 34 (jun/2009), são analisados livros entre um e oito anos de publicação, sendo também resenhada uma obra composta por textos do século XVI selecionados ${ }^{7^{3}}$ e traduzidos para o português. Os números 14 (jun/2004) e 24 (dez/2006) também manifestam essa tendência, publicando resenhas de obras com dois anos de publicação. Apenas eventualmente aparecem resenhas de obras de publicação mais antiga, como no número 04 (out/2001), cuja obra analisada data de 08 anos antes da edição em questão da revista.

A quantidade de documentos publicada por edição variou pouco ao logo do tempo: o maior número foi na edição Especial (ago/2010). Esta edição é um dossiê temático, que aborda assuntos relacionados a "Trabalho e Educação: questões teóricas e metodológicas". A escolha dos documentos procurou recuperar o debate sobre o Estado Novo, até o início da década de 1960. Foram disponibilizados quatro discursos: o discurso de Getúlio Vargas à Assembleia Legislativa em 1937, o discurso de Juscelino Kubitschek ao Congresso Nacional em 1960, e os discursos de Jânio Quadros e João Goulart ao Congresso Nacional em 1961. Nos números especiais, os documentos costumam relacionar-se à temática tratada nas outras publicações da revista. Em geral, o número de documentos publicados oscila entre um ou dois, sendo grande parte deles acompanhados de um comentário feito por quem o enviou à Revista. Muitos dos comentários procuram situar os documentos historicamente, bem como sua importância enquanto fontes para a historiografia da educação, como nos números 42 (jun/2011), 37 (mar/2010), 25 (mar/2007) e 15 (set/2004). Em algumas edições, como a 44 (dez/2011) e a 21 (mar/2006), o documento é apresentado digitalizado, sem comentários ou apresentações. No número 36 (dez/2009), apresentam-se apenas fragmentos de um documento, acrescidos de uma apresentação e contextualização mais consistente. Algumas vezes, os contribuintes relatam que o documento publicado fez parte do conjunto de fontes para elaboração de uma tese, como é o caso dos números 23 (set/2006) e 17 (mar/2005).

\section{Conclusões}

Hoffnagel (2006) afirma que, embora não haja um ensino explícito da utilização dos gêneros textuais entre alunos do ensino superior, é muito comum que eles sejam avaliados através de gêneros escritos. Percebe-se, através da análise dos primórdios da Revista HISTEDBR On-line, que este periódico constituiu-se um espaço para 
desenvolvimento da socialização acadêmica através da palavra escrita entre uma comunidade discursiva específica, que por questões políticas e epistemológicas possivelmente vinham tendo dificuldades de inserção no circuito acadêmico de publicações. Assim, a Revista analisada cooperou à formação de um grupo de autores, levando-os à utilização prática da escrita acadêmica, e ao consequente aprendizado das normas e formas de fazer próprias deste gênero. É possível que, a partir desse aprendizado, muitos dos autores tenham conseguido publicar em outros círculos, uma vez que o treinamento pode ter lhes auxiliado a melhorar a avaliação realizada sobre seus textos.

Com o passar do tempo, porém, a Revista caminhou em direção a uma ampliação de sua comunidade discursiva, com a inserção de publicações produzidas por autores de outros círculos acadêmicos e epistemológicos. Pode-se afirmar que as transformações sofridas pela HISTEDBR On-line caminharam em, pelo menos, duas direções. Uma delas diz respeito à caracterização do periódico como produtor de Letramentos Acadêmicos (Lea; Street, 1998). A outra se refere à adequação às normas de avaliação da Capes para os periódicos. $\mathrm{O}$ aumento na diversificação da comunidade discursiva, aliado à adequação às normas editoriais da ABNT, à publicação de artigos de autores de instituições estrangeiras reconhecidas e ao estabelecimento de um número médio de artigos por edição, faz parte dos critérios de avaliação do Qualis Periódicos ${ }^{8}$. A melhoria na classificação do periódico no Webqualis beneficia diretamente o grupo HISTEDBR, conferindo reconhecimento acadêmico e maior visibilidade ao trabalho realizado. Beneficia, também, os programas de pós-graduação que possuem alunos publicando nesta revista, uma vez que a avaliação dos periódicos influencia na avaliação institucional.

Embora o campo de História da Educação seja consistente, é interessante observar que o número de trabalhos publicados na HISTEDBR On-line que enfocam a historiografia educacional propriamente dita tem diminuído ao longo do tempo. Inácio Filho considera que esta crise está relacionada com a necessidade de a área da Educação se fazer vista, mas pode-se questionar se a diminuição de artigos do campo historiográfico esteja relacionada à posição de resistência epistemológica, assumida no passado pelo grupo HISTEDBR. É possível que essa resistência tenha causado o afastamento de um número significativo de instituições, orientadores e orientandos - que acabaram não se inserindo neste periódico quando foi iniciado o processo de maior abertura. Sem maiores atrativos para publicar no periódico analisado, e possuindo alternativas melhores classificadas no Webqualis para publicar ${ }^{9}$, os historiadores da educação passaram a ser menos representados na Revista, surgindo assim a lacuna para que cada vez mais autores da área da Educação ali publiquem.

Em consequência, foi adotada uma maleabilidade cada vez maior nas normas editoriais do periódico, permitindo que elas sejam ultrapassadas de acordo com o fluxo de artigos recebidos. A organização temática de cada volume acaba sendo uma característica mais forte da Revista do que a orientação quanto às linhas de pesquisa do periódico. Esta tendência, por um lado, pode acarretar uma descaracterização da HISTEDBR On-line enquanto publicação do campo da História da Educação ao longo do tempo, mas pode também servir como indicador das tendências de publicação na área da Educação.

\section{Referências bibliográficas}


CARVALHO, Marta Maria Chagas de. L'histoire de l'éducation au Brésil: traditions historiographiques et processos de rénovation de la discipline. Paedagogica Histórica, vol. 36, n. 3, 2000. p. 909-933.

CHARTIER, Roger. A história cultural: entre práticas e representações. Rio de Janeiro: Bertrand Brasil, 1990.

COMUNICADO no 002/2012 - Área de Educação. Atualização do Webqualis da área. Brasília: Coordenação de Aperfeiçoamento de Pessoal de Nível Superior, 2012. Disponível em

http://qualis.capes.gov.br/arquivos/avaliacao/webqualis/criterios2010_2012/Criterios_Qualis_2011 _38.pdf . Acesso em 27 de junho de 2012, 13h40min.

FISCHER, Adriana. O gênero rsumo no curso de Letras: eventos de letramento em discussão. Linguagem em (dis)curso, vol. 6, n. 3, set./dez. 2006. p. 442-454. Disponível em: http://www.revistainvestigacoes.com.br/Volumes/Vol.21.2/Judith_Hoffnagel.pdf . Acesso em 26 de junho de 2012.

HEMAIS, B.; BIASI-RODRIGES, B. A proposta sócio-retórica de John M. Swales para o estudo de gêneros textuais. In: MEURER, José Luiz; BONINI, Adair; MOTTA-ROTH, Désirée (Orgs.). Gêneros: teorias, métodos, debates. São Paulo: Parábola, 2005. p. 108129.

HOFFNAGEL, Judith Chambliss. Intertextualidade em textos universitários. Investigações, Recife, vol. 21, n. 2, jul./2008. p. 171-184. Disponível em http://www.revistainvestigacoes.com.br//volume-21-N2.html . Acesso em 26 de junho de 2012.

LEA, Mary R.; STREET, Brian. Student writing in higher education: na academic literacies approach. Studies in Higher Education, Abindgon, Oxon, UK, vol. 23, n.2, 1998. p. $157-172$.

QUALIS PERIÓDICOS. Brasília: Coordenação de Aperfeiçoamento de Pessoal de Nível Superior, 2012. Disponível em http://capes.gov.br/avaliacao/qualis . Acesso em 19 de maio de 2012, 08h30min.

REVISTA HISTEDBR ON-LINE. Campinas: Universidade Estadual de Campinas/Faculdade de Educação/HISTEDBR, 2000-, ISSN 1676-2584. Trimestral. Disponível em http://www.histedbr.fae.unicamp.br/. Acesso entre 15 de maio de $2011 \mathrm{e}$ 05 de junho de 2012.

SWALES, J. Genre analysis: English in academic na research settings. Cambridge: Cambridge UP, 1990.

WEBQUALIS. Brasília: Coordenação de Aperfeiçoamento de Pessoal de Nível Superior, 2012. Disponível em http://capes.gov.br/avaliacao/qualis . Acesso em 19 de maio de 2012, 09h00minhs. 


\section{Notas}

${ }^{1}$ UFMG

${ }^{2}$ Informações obtidas através do site do HISTEDBR On-line: http://www.histedbr.fae.unicamp.br/

${ }^{3}$ Por erro do servidor, até 22/05/2012 não foi possível acessar o artigo A Sociedade do Conhecimento no Conhecimento dos Educadores. Este, portanto, fica isentado na contagem de artigos por recorte temporal.

${ }^{4}$ Não serão analisadas as normas anteriores ao número 14 por não estarem acessíveis, devido a erro do servidor. Última tentativa: 05 de junho de 2012, 18:40hs.

5 A abreviatura f.s. significa que houve uma falha do servidor que impossibilitou o acesso ao conteúdo. Último acesso em 05 de junho de 2012.

${ }^{6}$ Excetuam-se do total de publicações as que não estavam disponíveis devido a falha do servidor.

${ }^{7}$ RATKE, W. Escritos sobre A Nova Arte de Ensinar de Wolfgang Ratke (1571-1635): textos escolhidos. Apresentação, tradução e notas de Sandino Hoff. Campinas, Autores Associados, 2008. Resenha por Cezar de Alencar Arnaut de Toledo e Marcos Ayres Barboza.

${ }^{8}$ Os critérios completos de avaliação dos periódicos da área de Educação pelo Qualis encontram-se disponíveis na página http://qualis.capes.gov.br/arquivos/avaliacao/webqualis/criterios2010_2012/Criterios_Qualis_2011_38.pdf .

${ }^{9}$ A Revista Brasileira de Educação, da ANPEd, e a Revista Brasileira de História da Educação, da SBHE, foram avaliadas no Webqualis como A1.

Recebido em setembro-2012

Aprovado em agosto-2013 